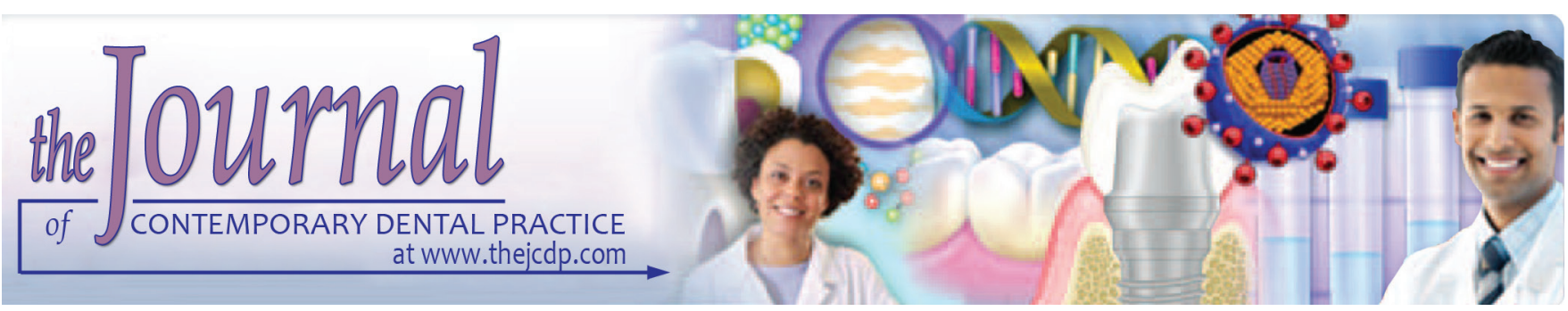

\title{
A Systematic Review of Amalgam Bonded Restorations: In vitro and Clinical Findings
}

\author{
${ }^{1}$ Ho CM Brian, ${ }^{2}$ Otto LT Lam, ${ }^{3}$ Nithya Jagannathan, ${ }^{4}$ Michael G Botelho
}

\begin{abstract}
Aim: This article aims to systematically review the evidence reporting on physical properties of bonded amalgam, its clinical performance, and implications.
\end{abstract}

Materials and methods: An electronic search in "Medline" (search term: Amalgam and Dentin bonding) from 1987 to 2013 yielded 465 publications out of which 170 articles were selected for the analysis. Data were extracted relating to the bond strength of amalgam to dentin, microleakage, postoperative sensitivity, and longevity of bonded amalgam restorations.

Results: A total of 129 in vitro studies out of 170 articles showed high bond strengths with filled adhesive resins and light-cured adhesives, in particular Amalgambond plus and Optibond adhesives. Thickness of bonding agent, type of alloy, and thermocycling showed inconclusive outcomes between bonded and nonbonded amalgam restorations. Majority of studies reported reduced microleakage when dentin bonding agents and resin-modified glass ionomer cements (RM-GICs) were used with amalgam. However, water stored, thermocycled, and spherical amalgam alloys resulted in higher microleakage. While bonded amalgam facilitated the retention of large restorations, reduction in postoperative sensitivity was not consistently observed between bonded and nonbonded amalgam restorations.

Conclusion: While bonded amalgam restorations reduce the need for mechanical retention conserving tooth structure and reducing the adverse effects of microleakage, there is lack of consistent evidence across all outcome domains to advocate the benefit of bonding of all amalgam restorations. Despite this, it can be considered the material of choice for large restorations and bonding enhances retention in vitro which can be considered beneficial clinically.

\footnotetext{
${ }^{1-4}$ Department of Prosthodontics, Faculty of Dentistry, The Prince Philip Dental Hospital, The University of Hong Kong, Sai Ying Pun, Hong Kong, China

Corresponding Author: Michael G Botelho, Department of Prosthodontics, Faculty of Dentistry, The Prince Philip Dental Hospital, The University of Hong Kong, Sai Ying Pun, Hong Kong, China, e-mail: botelho@hku.hk
}

Clinical significance: The use of adhesives to bond amalgam to the tooth structure offers potential advantages, as it helps in conservative cavity preparation without compromising the retention to tooth, making it a material of choice in large posterior restorations.

Keywords: Adhesives, Bond strength, Bonded amalgam, Longevity, Microleakage, Sensitivity, Systematic review.

How to cite this article: Brian HCM, Lam OLT, Jagannathan N, Botelho MG. A Systematic Review of Amalgam Bonded Restorations: In vitro and Clinical Findings. J Contemp Dent Pract 2018;19(8):1013-1024.

\section{Source of support: Nil}

\section{Conflict of interest: None}

\section{INTRODUCTION}

Dental amalgam has been a ubiquitous restorative material that has been used successfully for centuries to restore small and large cavities. Despite the use of composite restorative materials with advanced esthetics, amalgam is still considered as the restoration of choice for complex molar preparations due to its longevity, ease of use, and low cost. Recent literature has reported that amalgam restorations have an average lifespan of 15 years compared with composite resins which have a longevity of over 10 years and have annual failure rates of 0.16 to $2.83 \%$ compared with 0.94 to $9.43 \%$ for composites at 7 years. ${ }^{1}$ This is regardless of the tooth type and the number and dimensions of surfaces restored. ${ }^{2}$ In addition, the use of amalgam cores for crowns have a greater survival in terms of fracture resistance and durability compared with the resin and glass ionomer restorations. $^{3}$

However, while providing functional surfaces, it has limitations in restoring the strength of the tooth, is susceptible to secondary caries, is unesthetic and poses environmental concerns. ${ }^{4,5}$ In an attempt to improve the longevity and function of amalgam restorations, 
bonding agents have been used with the aim of improving retention, and reducing microleakage and secondary caries.

In vitro studies have demonstrated added retention and a reduction of microleakage with bonded amalgam, which suggests the potential for better clinical outcomes. ${ }^{6}$ Clinical studies, however, have shown variable results ${ }^{7-9}$ and a recent systematic review has questioned the benefit of bonding amalgam. ${ }^{10}$ Also, while a number of countries have banned amalgam ${ }^{11,12}$ or are in the process of doing so, ${ }^{13}$ there are many regions of the world that are unlikely to be able to do this due to resource or financial concerns. This suggests that amalgam restorations will still be placed for many years to come. ${ }^{13,14}$ There is a need to examine the literature on bonding amalgam with regard to in vitro and clinical data to inform practice despite its dwindling use.

The aim of this study is to perform a qualitative systematic review to evaluate both in vitro and in vivo evidence for bonding amalgam restorations.

\section{MATERIALS AND METHODS}

The aim of this review was to search the literature to identify the use of bonded amalgam, its clinical performance, and implications. The PubMed database was used to search for literature related to amalgam bonded to dentin. These included review papers, in vitro and in vivo studies from 1987 to 2013.

The inclusion criteria used were: Amalgam bonded to dentin; or bond strength of bonded amalgam; or microleakage of bonded amalgam restorations; or fracture resistance of bonded amalgam; or postoperative sensitivity after placement of bonded amalgam.

The exclusion criterion used was: Articles published in a language other than English.

The search keywords for PubMed were: ("Amalgam" AND “Dentin bonding").

After the PubMed search, 465 articles were initially found. After reading the titles and abstracts of the articles, 170 articles were selected, including 129 in vitro studies, 20 in vivo studies, and 21 review articles or short communications on the longevity and physical properties of amalgam restorations (Flow Chart 1).

\section{RESULTS}

The majority of the articles were in vitro studies. More than half of the articles were on bond strength of amalgam to dentin bonded with different adhesives. The remaining in vitro articles were related to microleakage, fracture resistance, and scanning electron microscope (SEM) studies, while in vivo studies focused on postoperative sensitivity and longevity.
Flow Chart 1: Selection process of articles included for the systematic review

465 publication identified from PubMed search as potentially relevant based on search term

"amalgam" and "dentin bonding"

Articles excluded for reason

articles published in language other than English

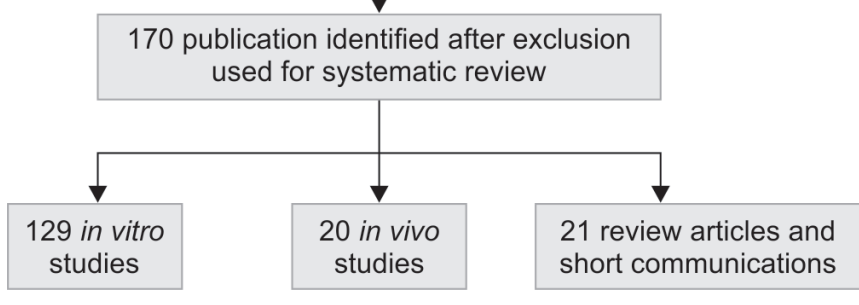

\section{In vitro Studies}

\section{Shear Bond Strength}

Thirty studies were found that examined the shear bond strength of amalgam to tooth tissue (enamel and dentin). The vast majority of these used resin cements, while a few used RM-GICs. One of the papers was excluded due to duplicate results in two of the papers by the same author. ${ }^{15,16}$ This resulted in 29 studies in total.

\section{Resin Cement}

The in vitro data of shear bond strength testing between amalgam and dentin showed a range of 3.89 to $37.4 \mathrm{MPa}$, using a range of testing protocols including the shear bond strength test and tooth model.

Prior to the $1990 \mathrm{~s}$, Shimizu et $\mathrm{al}^{17}$ reported a shear bond strength of 4.0 to $4.5 \mathrm{MPa}$ for Panavia and Superbond. In the early 1990s, Amalgambond appeared to be the main resin cement investigated, and a wide range of strength values (0.89-5.1 $\mathrm{MPa}$ ) were reported. Since 1994, with the availability of Amalgambond Plus with high performance additive (HPA) and All-Bond 2, bond strength values appeared to increase (6.23-14.57 $\mathrm{MPa})$. From 2000 onward, there was a wider range of resin cements available; however, the shear bond strength did not seem to show an observable increase (2.0-9.91 MPa).

It is realized that the large variation of values reported for the same products was due to the different design protocols implemented by different authors, including different cements, methodology, storage time, and thermocycling duration. Five of the 29 papers reported Amalgambond Plus with HPA to have some of the highest bond strengths. ${ }^{18-20}$ In addition, OptiBond was reported to have the highest or second highest (to Amalgambond Plus with HPA) bond strength to dentin. ${ }^{20-22}$ 
Out of all the resin cements bonded to dentin tested by different studies, Amalgambond Plus with HPA and OptiBond generally gave the highest or second highest bond strengths.

\section{Thermocycling}

Thermocycling has become a common feature of dental materials' bond strength testing as the luting agent and the bonding interfaces can all be affected by the thermal changes occurring after its setting time. Thermocycling can produce adverse physical effects on the bonded assembly due to different coefficients of thermal expansion between the tooth, the cement, and the bonded dental material. These thermal stresses can lead to microstructural changes resulting in alterations in the physical properties of the set resin cements. Thermocycling is often used when testing the durability of luting agents to tooth tissue.

The comparative effects of thermocycling to no thermocycling have only been shown in one study by Chang et al. ${ }^{23}$ One group of specimens was stored in $37^{\circ} \mathrm{C}$ distilled water for 24 hours, while the other was thermocycled between $5^{\circ} \mathrm{C}$ and $55^{\circ} \mathrm{C}$ for 1,000 cycles. The thermocycled and nonthermocycled specimens exhibited bond strengths of 9.07 and $10.02 \mathrm{~kg} / \mathrm{cm}^{2}$ respectively, a significant reduction of $9.5 \%$. The authors concluded that thermocycling adversely affects the shear bond strength of amalgam to dentin. While twelve other studies reported thermocycling, these did not incorporate a control of specimens not subjected to thermocycling.

One study showed thermocycling to adversely affect the shear bond strength of amalgam to dentin by $9.5 \%$.

\section{Storage Time}

Storage time in water is another common test condition for examining the durability of amalgam and dentin bonding, and evaluates the stability of the hybrid layer and the degree to which the bond will undergo hydrolysis over a period of time. ${ }^{24}$

Amalgam dentin bonded specimens are usually stored for a certain period of time before they are tested in a universal testing machine. The majority of shear bond strength studies have examined storage periods of 24 hours and 1 week, ${ }^{25}$ while other studies have assessed longer durations of more than 2 months. ${ }^{15,26}$

Only two of the studies compared the effect of different storage time. In a study by Imbery et al, ${ }^{16}$ water storage of either 3 or 6 months did not significantly affect the resistance of the specimens tested. This was also supported by Hasegawa et $\mathrm{al}^{25}$ who demonstrated that shear bond strengths were not adversely affected by the duration of storage in saline for up to 48 weeks. While limited, these studies seem to suggest that the amalgam bond to resin cement-treated dentin appears relatively stable in vitro without thermocycling.

Storage time had no significant effect on the bond strength.

\section{Thickness of Cement}

The thickness of different bonding agents and its influence on the bond strength have been mentioned in some of the studies, although this was not one of the original primary outcomes. Difference in film thickness was observed during SEM studies after shear bond strength testing and then extrapolated to their bond strength.

Grobler et $\mathrm{al}^{18}$ investigated the bonding of amalgam to dentin with four different cements and concluded from SEM images that resin-dentin hybrid layers of different thicknesses did not have any significant effect on the bond strengths. In contrast, other studies have demonstrated higher bond strengths with greater film thickness, ${ }^{19,20,22}$ this possibly being explained by the production of a resin-amalgam interdiffusion layer which facilitates micromechanical locking, thereby enhancing bonding. This is supported by Pashley et al, ${ }^{27}$ who considered the infiltration of adhesive resin into demineralized dentin from caries or acid etching important to produce long-term stable bonds compared with those that only partially infiltrate the demineralized zone for amalgam or composite bonding.

Studies on cement thickness were controversial, some found to have no effect while others found that greater cement film thickness produced higher bond strength.

\section{Volume of Adhesive}

The amount of bonding agent used to obtain the best bond strength from the adhesive has been a concern. It is often thought that the tooth should be flooded with adhesives to provide optimal dentin bonding and micromechanical retention with amalgam. Excessive resin cement, however, can also make the carving of the amalgam more difficult and result in an excess of resin extending down the root surface. Therefore, studies have also examined differences in bonding provided by sufficient wetting or excessive wetting of the dentin surface.

Overton and Vance ${ }^{28}$ reported no effect of increasing the volume of adhesive applied to the tooth surface on bond strength as long as the surface of the prepared tooth is completely wet with Amalgambond Plus with HPA. Likewise, Barkmeier et $\mathrm{al}^{29}$ found that an increased number of applications of Amalgambond Plus did not increase bond strength.

Increasing the volume of adhesive had no significant effect on the bond strength. 


\section{Condensation Technique}

Proper amalgam condensation results in optimal physical properties and mechanical condensation have been used with the benefits of consistent and efficient condensing force. In an attempt to compare the effect of mechani$\mathrm{cal}$ and hand condensation, Ratananakin et $\mathrm{al}^{20}$ found that there was no statistical difference in the shear bond strength of amalgam bonded to dentin, although the thickness of the resulting cement was not measured.

There were no significant effects of condensation technique on bond strength, but based on only one study.

\section{Filled vs Unfilled}

The addition of filler particles to the adhesive resin of newer generation dentin bonding agents available after the mid-1990s resulted in a notable increase in amalgam to dentin bond strengths. ${ }^{30-32}$ It was reported by Li et al ${ }^{33}$ and Braem et $\mathrm{al}^{34}$ that the physical properties of resin composite increase with an increase in filler content.

It has been demonstrated by several studies that an increase in filler particles results in higher shear bond strengths due to a thicker and more viscous adhesive layer. ${ }^{19,20,22,30,35}$ In an update to Amalgambond Plus, a HPA powder was added, which was claimed to slow polymerization, allowing more time for the monomers to penetrate a dry dentinal surface as well as increasing the physical properties of the bonding agent. Grobler et $\mathrm{al}^{18}$ mentioned that HPA methacrylate fibers increase the density of the mixture of Amalgambond Plus and form greater entrapment between the filler and amalgam particles, which more than doubled the bond strength from 2.6 to $7.2 \mathrm{MPa}$.

Filled cements produce better shear bond strength than unfilled cements.

\section{Light Cure vs Chemical Cure}

Resin cements can be activated by chemical activation (self-cured), photo-activated, or dual-cured cements. Chemically activated materials uniformly set even at the bottom of deep cavities, where access for curing light is limited. Photo-activated materials and their set-oncommand capability can have a longer working time. de Menezes et $\mathrm{a}^{36}$ showed that the autopolymerizing system and one of the dual-polymerizing systems were as effective as the light-activated systems in bonding indirect composite restorations to dentin. To examine the effect of different activation modes, studies examine different types of bonding agents with different setting reactions together.

Several studies showed similar or higher bond strengths when adhesives were light-cured prior to amalgam placement compared with chemical cured. ${ }^{32}$
This was also supported by the results of Cianconi et $\mathrm{al}^{37}{ }^{37}$ who reported that light curing produced better shear bond strength than chemical curing, especially when a spherical alloy was used. In addition, they found that the adhesive interfaces of light-cured material were relatively thick (Prime and Bond NT DC, 6-7 $\mu \mathrm{m}$ ), while the chemically cured adhesives were "relatively thin" $(2-4 \mu \mathrm{m})$. Ruyter ${ }^{38}$ mentioned that light curing initiates the setting reaction and allows the bottom layer of resin to bond to dentin while the surface layer remains unpolymerized due to the air inhibition layer. When amalgam is condensed against an air-inhibited layer, oxygen is eliminated which allows resin to polymerize more completely and bond mechanically to amalgam. ${ }^{21}$ Other studies state that Amalgambond must be wet and of sufficient thickness to be incorporated into amalgam, where amalgam is condensed into unset cement. ${ }^{15}$

Light-cured adhesives result in higher shear bond strength compared with chemical curing.

\section{Spherical and Admixed Alloy}

Some studies have investigated whether amalgam bonding is influenced by the type of amalgam used. Spherical amalgam has high plasticity and a more fluid mix, allowing it to be condensed more easily with lighter force. Spherical amalgam also has lower mercury content, as it requires less mercury to wet the particles and it sets faster than lathe-cut amalgam. Lower mercury content results in less mercury-containing reaction products $(\gamma 2$ phase) which are softer and weaker. Admixed amalgam (Dispersalloy) is a mixture of lathe-cut and spherical alloys. These factors might affect the handling and performance of the amalgam.

The difference in bond strength associated with the two types of amalgam alloys has been controversial, although available evidence suggests a trend toward higher bond strengths with the spherical alloy. The hypothesis proposed to support the high performance of spherical alloy was that admixed alloy has a slower setting time which was hampered by the removal of mold used during condensation which disturbed the final set and created stress which weakened the bond. Spherical amalgam particles have a larger surface area, increasing the contact area with adhesive. Cianconi et $\mathrm{al}^{37}$ showed that admixed alloy exhibited both lower bond strengths and less residual amalgam on the debonded dentin surface, meaning that adhesive failure occurs between the adhesive and amalgam, resulting in an adhesive failure. Morrill et $\mathrm{al}^{39}$ found that spherical alloy had significantly higher SBS to both composite and dentin than did admixed alloy when bonded with Amalgambond. However, Cooley et $\mathrm{al}^{40}$ found no differences between 
spherical and admixed alloy when bonded with Amalgambond.

Some studies showed that spherical alloy produced higher bond strength than admixed amalgam alloy while another study showed no difference when bonded with Amalgambond.

\section{Resin-modified Glass Ionomer Cement}

The majority of the studies investigating amalgam bonding have mainly compared resin cements rather than RM-GICs or GIC. Only three studies on RM-GIC were retrieved in the literature search, which is perhaps a reflection of the greater popularity of resin cements. ${ }^{41-43}$ One study reported better bond strength with light-cured RM-GIC (Vitrebond) compared with Amalgambond or Panavia EX. ${ }^{41}$ On the contrary, Belcher and Kunsemiller ${ }^{42}$ reported higher bond strengths with Amalgambond compared with RM-GIC. In the third study, Dhanasomboon et $\mathrm{al}^{43}$ reported that application of two layers of resin bonding agents and/or RM-GICs with light polymerization in between resulted in significantly higher shear bond strength than single applications than single coats.

Two out of three studies showed that RM-GIC produced higher bond strength, while one study showed a high bond strength with Amalgambond.

\section{Tensile Bond Strength}

Like shear bond strength testing, tensile bond strength testing shows a similar variance of test materials and methodologies and with a diverse range of results that also makes comparisons between studies unmeaningful. Four studies were identified.

While Miller et $\mathrm{al}^{44}$ found that amalgam allowed to set for 1,6, or 24 hours prior to adhesion with Amalgambond to dentin had a higher bond strength than freshly condensed amalgam, however, one must question the clinical relevance of this finding, as it is not clinically practicable. In contrast, Garcia-Barbero et $\mathrm{al}^{45}$ reported high tensile bond strength with freshly triturated amalgam and cured resin when compared with composite and set amalgam. They also reported that the thickness of adhesive resin should be minimal, as a thicker resin layer may be the cause cohesive failure of amalgam restorations.

In a comparison of dentin pretreatment $v$ s no pretreatment when using dentin conditioners prior to All-Bond, ${ }^{46}$ no significant difference was observed in the tensile bond strength. ${ }^{46}$ Muniz et $\mathrm{al}^{47}$ evaluated three different adhesive systems and different setting modes for amalgam to dentin. They reported the "highest" tensile bond strengths was observed when Optibond dual-cure adhesive system was light-cured.
The in vitro tensile bond strength data showed diverse outcomes. Use of conditioners or light curing of resins was not harmful to strength results.

\section{Glass ionomer and Amalgam Bonding}

Based on an in vitro study by Chen et al, ${ }^{41}$ bond strengths produced by Fuji-II glass ionomer to amalgam were equivalent to those of Amalgambond Plus and Panavia21. This study also tested the fracture strength obtained with the application of these three agents onto molar mesial, occlusal, and distal (MOD) cavities, and no statistical differences were found when compared with intact teeth. This suggests that a GIC adhesive liner may improve the strength of MOD amalgam-restored teeth.

In one study, GIC has shown similar bond strength to amalgam resin cements and can improve the strength of teeth in vitro.

\section{Microleakage}

The interfacial gap between amalgam and adjacent tooth structure has been reported to be 2 to $12 \mu \mathrm{m} .{ }^{48}$ Factors which may contribute to gap formation and microleakage include: Lack of chemical adhesion, dimensional changes on setting of the amalgam, different thermal coefficients of expansion, inadequate trituration, and poor cavity wall adaptation. This gap between amalgam and dental structure causes problems ${ }^{49}$ of penetration of bacteria, "food residue," and salivary components which may cause postoperative sensitivity, discoloration of the tooth, marginal deterioration, secondary caries, and possible pulpal irritation. ${ }^{50}$

Freshly placed amalgam is said to undergo active corrosion at the interface between the tooth and the restoration over time from microleakage of electrolytes along the interfacial gap. Corrosion products, especially tin products $\left(\mathrm{SnO}_{2}, \mathrm{SnCl}_{2}\right.$, and $\left.\mathrm{Sn}(\mathrm{OH})_{2} \mathrm{Cl}\right)$ and smaller amounts of calcium and phosphorus, ${ }^{51}$ will build up over time and gradually seal the interface ${ }^{52,53}$ Corrosion products have also been shown to reduce microleakage. ${ }^{49}$ The lack of "self-sealing" ability in high copper alloys due to low levels of corrosion-susceptible gamma 2 phase, however, may result in substantial microleakage for up to 18 months in vitro. ${ }^{54}$

Development of dentin bonding agents has led to the use of adhesive agents to bond amalgam restorations to minimize amalgam microleakage as well as to gain additional retention and protect the dentin/pulp complex. ${ }^{55}$

\section{Pattern of Microleakage}

Dye leakage has been found to be greater at the cementum/dentin margins than enamel. ${ }^{6,56}$ This is due to the difference in mineral composition between the two 
substrates. Dentin has a higher organic compound composition and is also a moist tissue, resulting in more unstable bonds between the tooth and the adhesive. ${ }^{57}$

Turner et $\mathrm{al}^{58}$ found that microleakage mainly occurs at the amalgam/resin liner interface rather than the resin/dentin interface, supporting the results of previous studies. ${ }^{40,55,59}$ Tangsgoolwatana et al, ${ }^{60}$ however, found that greater leakage appeared to occur between the liner and the tooth than between the liner and the amalgam, and suggested that the collapsed collagen on the dentin surface layer may prevent the full depth penetration of dentin bonding agent.

Toledano et $\mathrm{al}^{61}$ reported SEM evaluations of class $\mathrm{V}$ bonded amalgam restorations after thermocycling, and observed the presence of voids along the axial wall. Two of the agents they tested, OptiBond and AElitebond, experienced microleakage between the enamel and adhesive system and/or between the amalgam and the adhesive, but this was not evident with Panavia.

Sano et $a l^{62}$ defined the term "nanoleakage," where diffusion of small ions and molecules occurs throughout the dentin hybrid layer in the absence of gap formations. Their study found that with the absence of gap formation, silver nitrate could migrate along the porous zone at the base of the hybrid layer. This type of penetration is probably related to the small size of the silver ion allowing penetration.

However, Gale and Darvell ${ }^{63}$ have questioned the microleakage models as since dentin is permeable, it is a confounding factor in tracer penetration tests due to interand intratubule connections. Therefore, test results will be affected by the entry of tracer independent of the presence of any marginal gaps, giving false-positive results.

The amalgam-resin interface can be penetrated by dye easier than resin-tooth interface.

\section{Effects on Microleakage}

Many studies show that adhesive resin can effectively reduce leakage around amalgam restorations ${ }^{17,64-69}$ and found that resin bonding to dentin did not significantly reduce leakage when compared with dentin alone. ${ }^{67}$ However, Silva e Souza Junior et $\mathrm{al}^{70}$ found no difference in microleakage between bonded and nonbonded amalgam restorations.

Although some studies found no effect, most studies showed that bonded amalgam with resin cements reduced microleakage around amalgam restorations.

\section{Thermocycling}

Helvatjoglou-Antoniades et $\mathrm{al}^{71}$ have shown that after thermocycling, there was a significant increase in microleakage when compared with the nonthermocycled group. They explained that this was due to the difference in the coefficient of thermal expansion between enamel $\left(11.4 \mathrm{ppm}^{\circ} \mathrm{C}^{-1}\right), \operatorname{dentin}\left(8 \mathrm{ppm}^{\circ} \mathrm{C}^{-1}\right), \operatorname{amalgam}\left(25 \mathrm{ppm}^{\circ} \mathrm{C}^{-1}\right)$, and composite resin $\left(25-60 \mathrm{ppm}^{\circ} \mathrm{C}^{-1}\right){ }^{72}$ which may lead to the creation of gaps and subsequent microleakage after thermocycling.

Thermocycling significantly reduced bond strength due to difference in the coefficient of thermal expansion leading to gap creation, which will lead to microleakage.

\section{Water Storage/Aging}

Saiku et $\mathrm{al}^{59}$ compared the effect of aging on the microleakage of bonded amalgam at 24 hours and 30 days using Amalgambond, copal varnish, and no lining. They showed that non-aged Amalgambond-lined teeth showed significantly less microleakage than after aging for both resin/ enamel and resin/dentin interfaces. The increased microleakage shown in the aged Amalgambond-lined restoration suggests that interfacial resin may undergo hydrolytic degradation, indicating a level of resin liner breakdown. Nakabayashi et $\mathrm{al}^{24}$ suggested that after long-term immersion in water, deterioration of the 4-methacryloyloxyethyl trimellitate anhydride (META) adhesion occurs in a band of exposed collagen that lies between the "hybrid" dentin layer and the unaltered dentin. Ben-Amar et $\mathrm{al}^{73}$ also showed that after aging with water, microleakage significantly increases.

Water storage significantly increases microleakage of the restoration margins.

\section{Spherical vs Admixed Amalgam}

Several studies examined the effects of different amalgam alloys on microleakage with various dentin bonding agents or resin liner systems. Turner et al, ${ }^{58}$ Tangsgoolwatana et $\mathrm{al}^{60}$ and Korale and Meiers ${ }^{49}$ found that the choice of alloy had no significant effect on the microleakage scores. On the contrary, Mahler and Nelson ${ }^{74}$ showed that spherical alloy (Tytin) had a greater tendency for marginal microleakage than admixed alloy (Dispersalloy). Helvatjoglou-Antoniades et $\mathrm{al}^{71}$ compared Orosphere Plus (admixed), Indiloy (spherical), Oralloy (spherical), and gallium. They found that Oralloy has a significantly higher microleakage when compared with the other three alloys and suggested that it was due to the high tin content of Oralloy which affected the dimensional stability.

Spherical amalgam alloys have a significantly higher microleakage.

\section{Resin-lined vs Dentin Bonding Agents Alone}

Most of the earlier studies employed only dentin bonding primers prior to amalgam condensation for testing 
microleakage. ${ }^{49}$ Turner et $\mathrm{al}^{58}$ demonstrated that using the dentin bonding primer and resin bonding may help to reduce microleakage which may minimize the risk of recurrent caries or postoperative sensitivity. Korale and Meiers ${ }^{49}$ duplicated the microleakage study of Turner using the same bonding systems, but without the viscous liners. They showed that dentin bonding primer restorations had significantly less microleakage at both the occlusal and gingival margins than Copalite and unlined restorations, which is in agreement with Berry et al. ${ }^{54}$ They also concluded that the rationale for using dentin bonding agent with amalgam is to prevent microleakage, while the addition of the resin liner is to form mechanical interlocking with the amalgam in order to aid in amalgam retention.

Berry et $\mathrm{al}^{54}$ compared the microleakage of etched and nonetched class I occlusal amalgam restorations. These were treated with different dentin bonding system primers. They found that acid-etched restorations permitted significantly less microleakage than Copalite, nonetched, and unlined restorations.

Dentin bonding agent helps to reduce microleakage, while the use of resin cements increases bonded amalgam bond strength.

\section{Dual-cure vs One-bottle Adhesive}

Briso et $\mathrm{al}^{55}$ in their study concluded that dual-cured adhesives reduced microleakage around amalgam more effectively than "one-bottle" adhesives. However, only one of the dual-cured cements, Scotchbond Multipurpose Plus, showed significantly better control of dye penetration, while the other two dual-cured cements performed similarly to the "one-bottle" cement.

There are mixed results with dual-cure adhesives generally showing reduced microleakage.

\section{Bond Strength and Microleakage}

Muniz et $\mathrm{al}^{47}$ have shown that there is no positive correlation between sealing and retention properties of adhesives. Although differences between adhesives were found for bond strength testing, the microleakage evaluation failed to demonstrate a relationship. ${ }^{18,75-77}$ This seems to suggest that there is no correlation between sealing and retention.

There is no positive correlation between sealing and retention of restorations.

\section{Resin-modified Glass Ionomer}

da Silva et $\mathrm{al}^{78}$ found that resin-modified glass ionomer produced the lowest leakage in cementum/dentin margins when compared with copal varnish and resin cements (RelyX ARC, Single Bond and Alloybond). They explained that this could be attributed to the high dimensional stability of the material, lower thermal conductibility, as well as chemical adhesion to dentin. ${ }^{6}$ Other studies also agree with da Silva et $\mathrm{al}^{78}$ that RM-GIC produced the lowest leakage. ${ }^{6,79,80}$ de Morais et al ${ }^{80}$ also found that resin-modified glass ionomer significantly decreased microleakage and was shown to perform significantly better than Panavia Ex.

Resin-modified glass ionomer produced the lower microleakage compared with resin cements.

\section{Clinical Studies}

\section{Complex Amalgam Restorations: Pins vs Bonded}

In a prospective clinical trial comparing 60 bonded and amalgam pin-retained complex amalgam restorations after 5 and 6 years, failures were reported for eight pinretained and three bonded restorations. ${ }^{81,82}$ No significant differences in failure rate, marginal adaptation, marginal discoloration, secondary caries, tooth sensitivity, or tooth vitality were found. The authors concluded that bonding with a filled, 4-META-based bonding resin appears to be a viable alternative to dentin pins.

In a shorter study of 2 years' duration, Amalgambond Plus used with or without HPA was compared with dentin pin-retained restorations. ${ }^{83}$ All restorations were "completely retained and rated alpha." These authors also concluded that amalgam adhesive is an alternative to pins, although the study was only short term.

Davis and Overton ${ }^{84}$ compared bonded amalgam with pin-retained amalgam in teeth with "incomplete fractures" and reported that both treatments were successful in reducing chewing sensitivity in "cracked molars" up to a period of 1 year. They suggest that bonded amalgam may be preferred over mechanically retained complex amalgam restoration with incomplete fracture; however, this study was not a long-term review.

Amalgam bonding can successfully retain large restorations and reduce chewing sensitivity.

\section{Postoperative Sensitivity}

Postoperative sensitivity following amalgam restorations is a possible sequelae to this dental treatment and it negatively affects the patient's dental experience. It has been considered to occur due to microleakage around the restoration. ${ }^{85}$ However, over time, corrosion products are thought to seal the restoration, reducing microleakage and so reducing the sensitivity. ${ }^{86}$

A long-term double-blinded study by Smales and Wetherell ${ }^{87}$ reviewed other studies on the clinical performance of 366 premolar and molar bonded amalgam restorations placed in classes I and II cavities with five dentin/amalgam bonding agents over a period of up to 
5 years. Five restorations failed and no pulpal sensitivity or recurrent caries were reported. They reported that the use of "adhesive lining materials may offer few long-term advantages over non-bonded amalgam restorations." However, there was no comparison with nonbonded restorations in their analysis, so one may question their conclusion.

Mahler et al ${ }^{88}$ investigated the use of Panavia 21 on 100 classes I and II amalgam restorations, and reported no benefits for the bonded restoration with regard to marginal fracture and short-term postoperative sensitivity after 1 year. The same author ${ }^{9}$ performed a follow-up evaluation at 3 years. They found no significant differences in postoperative sensitivity and marginal fracture between bonded and nonbonded restorations.

Patient symptoms were investigated in a doubleblinded randomized clinical trial comparing Amalgam Bond Plus and Copalite with Vitrebond, among 60 class I and II restorations of different depths. ${ }^{89}$ Cold response measures and self-reported questionnaires suggested that those who had bonded (Amalgam Bond Plus) restorations were less sensitive to cold stimulus 1 week after treatment compared with baseline. Subjects with Liner and Vitrebond (Copalite/Vitrebond) were more sensitive after 1 week compared with the baseline. Therefore, the authors concluded that Amalgambond can reduce sensitivity to a stimulus.

In a double-blinded clinical trial examining postoperative cold sensitivity, Browning et $\mathrm{al}^{89}$ evaluated the use of OptiBond in class I or II amalgam restorations of different depths, and were unable to observe significant differences with a control group 1 week after treatment. It was concluded that OptiBond does not reduce sensitivity to a stimulus. Similar results were also reported in two additional studies that evaluated postoperative sensitivity ${ }^{90,91}$ with OptiBond.

Subay et $\mathrm{al}^{92}$ investigated the pulpal response to Scotchbond Multipurpose Plus bonding agent in noncarious class $\mathrm{V}$ cavities. A traditional class $\mathrm{V}$ cavity was performed on premolars of patients who were undergoing orthodontic treatment and were extracted after 10 and 35 days. While histological examination showed that Scotchbond multipurpose Plus did "not exhibit significant deleterious effects on the human pulp tissue during the test period," it caused more pulpal reaction than dycal with zinc oxide and eugenol restorations, although no statistical analysis was performed.

Studies' results were controversial, some found to have no difference in postoperative sensitivity between bonded and nonbonded amalgam restoration while others found Amalgambond restoration to reduce postoperative sensitivity.

\section{DISCUSSION}

This article systematically analyzed the performance and clinical success of bonded amalgam restorations. The PubMed database was used and the reference list for bonded amalgam featured 465 articles of which 170 articles were selected for the systematic review. While the in vitro studies focused on shear bond strength, tensile bond strength, and microleakage of bonded amalgam restorations in vivo studies were primarily on postoperative sensitivity. The results of this study seem to support that the bond strength of amalgam bonded restorations has similar clinical outcomes to nonbonded restorations. However, addition of filler particles, lightcured adhesives, and the use of spherical alloy resulted in higher shear bond strength. The tensile bond strength was increased when the amalgam was allowed to set prior to its adhesion to dentin. The results of our analysis showed reduced microleakage when dentin bonding agents and RM-GIC were used as adhesives. However, the use of spherical alloys, aged amalgam bonded restorations, and thermocycling increased microleakage of the restoration margins. The analysis of in vivo studies showed that amalgam adhesives were preferred over pins for retaining complex restorations and the postoperative sensitivity was similar for both bonded and nonbonded amalgam restorations.

For generations, dental amalgam has been considered as the clinically preferred primary restorative material in areas of the mouth where esthetics is not of concern due to its excellent physical properties, safety, efficacy, and longevity. ${ }^{93}$ There have been, however, controversies and debate regarding the use of amalgam in dentistry due to potential mercury release and its adverse effects on health and the environment. This has led practitioners to explore alternative dental restorations. ${ }^{11}$ Studies by Risher ${ }^{94}$ and Dye et $\mathrm{al}^{95}$ have reported that an increased number of amalgam restorations in children resulted in increased urinary mercury concentrations which would be of concern as prolonged exposure may lead to renal, neurological, and immunological impairments. However, several other studies assessed the health effects from mercury exposure related to dental amalgam and did not report any significant adverse effects. ${ }^{96,97}$

The use of amalgam has declined in higher income countries $^{93,98,99}$ and it has also been banned in countries like Norway, ${ }^{100}$ Sweden, ${ }^{101}$ and some states in the United States, as they considered mercury release from amalgam restorations to be a dangerous environmental toxin. In other parts of Europe, countries like Denmark, Italy, Finland, and Estonia use amalgam restorations for less than $5 \%$ of carious lesions. ${ }^{102}$ Amalgam restorations have been used restrictively in Japan and Switzerland. ${ }^{102} \mathrm{~A}$ 
number of other countries like France, Austria, Canada, Finland, and Germany have also minimized the use of amalgam restorations, restricting their use in pregnant women, in children under 6 years of age, and in patients with kidney problems. ${ }^{103}$

Several studies have reported a lack of evidence of any adverse health effects on clinicians handling amalgam and the patients who receive it. It has also been stated that the residual mercury disposal does not contribute to a significant source of environmental mercury. ${ }^{104}$ This was supported by several organizations like World Health Organization (WHO), World Dental Federation (FDI) and International Association for Dental Research, as a ban on amalgam would result in substantial increases in oral health disparities. ${ }^{105}$

While in 2009, at the FDI at the general Assembly, amalgam was stated as being a safe restorative affordable material for the majority of communities around the world who are in need of dental treatment, ${ }^{105}$ it later described in a policy statement the intent to phase down the use of dental amalgam. ${ }^{106}$ The elimination or phaseout of amalgam in dental restorations was first proposed by United Nations Environment Programme in collaboration with $\mathrm{WHO}^{93}$ to eradicate the release of mercury vapors and other by-products during the manufacture, processing, and transport of mercury. However, the term "phase-down" was adopted to replace "phase-out," as complete elimination of amalgam requires developing an alternative material with better properties for use. The Minamata Convention on Mercury conducted in 2013 put forward nine provisions on dental amalgam to lead to a worldwide reduction in mercury release into the environment. ${ }^{106}$ The Minamata convention also proposed a ban of mercury-containing nondental products and to phase out the use of dental amalgam by 2020 to protect human health and the environment from mercury toxicity. ${ }^{13,107}$

The trend toward mercury-free dentistry by phasing down and eventually phasing out dental amalgam has forced dentists all over the world to consider using an alternative restorative material. Unfortunately, these alternatives are expensive and so the potential cost incurred by the patients has raised concerns regarding the implication of dental health care, especially in underdeveloped and developing countries. A ban on amalgam restorations is expected to have a financial impact on both dentists and patients. Most often, people from urban areas and higher income groups are not affected due to decreased oral health needs and increased accessibility to dental health care. However, the most heavily affected populations will be those of lower and middle socioeconomic strata having poor oral health, ${ }^{108}$ as they will have no other option but to choose the more expensive composite restorations which have a reported lower longevity than amalgams. ${ }^{109}$
This may lead to increased restoration replacement and associated financial and biological costs, or patients not seeking required dental care, leaving caries untreated or requiring tooth extraction, both of which may leave the patient in distress. Hence, a complete ban on amalgam would adversely affect the oral health of lower socioeconomic populations, as a lack of financial resources to afford composite may mean extraction of restorable teeth.

While composite resin restorations have been adopted as an alternative restorative material in most countries, they pose biocompatibility issues through the release of toxic substances from the components of restorative material. ${ }^{110}$ Concerns have been revolving around the release of bisphenol A (BPA) from composite restorations. They are reported to have cytotoxic effects which may lead to pulp irritation and gingival inflammation, ${ }^{111}$ as well as potential effects on chromosomes, resulting in several systemic complications. ${ }^{111,112}$ Despite the evidence that BPA and other toxic substances leach from composite resins, these restorative materials are used almost globally, which could probably be due to the existence of BPA in most of the plastic products and household appliances used on a daily basis. Hence, the use of composite as an alternative to dental amalgam cannot be conclusively justified, and the potential long-term effects of these alternative dental materials should be thoroughly examined before considering the complete phase-out of conventional amalgam restoration.

Despite the desire and need to reduce amalgam use based on environmental concerns and move toward mercury-free restorations, there is a high cost involved both financially and potentially biologically. This means that amalgam restorations will continue to be necessary for the treatment of dental caries in regions of the world with limited dental resources and in population groups with health financing challenges, and as such, amalgam will remain a necessary restorative material for the foreseeable future.

\section{CLINICAL SIGNIFICANCE}

The use of adhesives to bond amalgam to the tooth structure offers potential advantages, although there is inconsistency in results when compared with nonbonded amalgam. However, bonded amalgam helps in conservative cavity preparation without compromising the retention to tooth, making it a material of choice in large posterior restorations.

\section{REFERENCES}

1. Christensen GJ. Longevity of posterior tooth dental restorations. J Am Dent Assoc 2005 Feb;136(2):201-203.

2. Antony K, Genser D, Hiebinger C, Windisch F. Longevity of dental amalgam in comparison to composite materials. GMS Health Technol Assess 2008 Nov;4:Doc12. 
3. Wassell RW, Smart ER, St George G. Crowns and other extracoronal restorations: cores for teeth with vital pulps. Br Dent J 2002 May;192(9):499-502, 505-509.

4. Mahler DB, Bryant RW. Microleakage of amalgam alloys: an update. J Am Dent Assoc 1996 Sep;127(9):1351-1356.

5. Shenoy A. Is it the end of the road for dental amalgam? A critical review. J Conserv Dent 2008 Jul-Sep;11(3):99-107.

6. Cenci MS, Piva E, Potrich F, Formolo E, Demarco FF, Powers JM. Microleakage in bonded amalgam restorations using different adhesive materials. Braz Dent J 2004 Aug;15(1): 13-18.

7. Setcos JC, Staninec M, Wilson NH. A two-year randomized, controlled clinical evaluation of bonded amalgam restorations. J Adhes Dent 1999 Winter;1(4):323-331.

8. Mach Z, Regent J, Staninec M, Mrklas L, Setcos JC. The integrity of bonded amalgam restorations: a clinical evaluation after five years. J Am Dent Assoc 2002 Apr;133(4):460-467.

9. Mahler DB, Engle JH. Clinical evaluation of amalgam bonding in class I and II restorations. J Am Dent Assoc 2000 Jan;131(1):43-49.

10. Opdam NJ, van de Sande FH, Bronkhorst E, Cenci MS, Bottenberg P, Pallesen U, Gaengler P, Lindberg A, Huysmans MC, van Dijken JW. Longevity of posterior composite restorations: a systematic review and meta-analysis. J Dent Res 2014 Oct;93(10):943-949.

11. Edlich R, Mason SS, Chase ME, Fisher AL, Gubler K, Long WB 3rd, Newkrik AT. Revolutionary advances in the prevention of demyelinating diseases. J Environ Pathol Toxicol Oncol 2009;28(2):143-152.

12. Jones DW. Has dental amalgam been torpedoed and sunk? J Dent Res 2008 Feb;87(2):101-102.

13. Mackey TK, Contreras JT, Liang BA. The Minamata Convention on Mercury: attempting to address the global controversy of dental amalgam use and mercury waste disposal. Sci Total Environ 2014 Feb;472:125-129.

14. The International Academy of Oral Medicine and Toxicology. A comprehensive review of the toxic effects of mercury in dental amalgam fillings on the environment and human health. The toxic effects of dental amalgam. ChampionsGate (FL): IAOMT; 2016. [cited 2016 Feb 8]. p. 1-26. Available from: https://iaomt.org/wp-content/uploads/ComprehensiveReview-Dental-Mercury.pdf.

15. Imbery TA, Burgess JO, Batzer RC. Comparing the resistance of dentin bonding agents and pins in amalgam restorations. J Am Dent Assoc 1995 Jun;126(6):753-759.

16. Imbery TA, Hilton TJ, Reagan SE. Retention of complex amalgam restorations using self-threading pins, amalgapins, and Amalgambond. Am J Dent 1995 Jun;8(3):117-121.

17. Shimizu A, Ui T, Kawakami M. Bond strength between amalgam and tooth hard tissues with application of fluoride, glass ionomer cement and adhesive resin cement in various combinations. Dent Mater J 1986 Dec;5(2):225-232.

18. Grobler SR, Oberholzer TG, Rossouw RJ, Grobler-Rabie A, Van Wyk Kotze TJ. Shear bond strength, microleakage, and confocal studies of 4 amalgam alloy bonding agents. Quintessence Int 2000 Jul-Aug;31(7):501-508.

19. Bagley A, Wakefield CW, Robbins JW. In vitro comparison of filled and unfilled universal bonding agents of amalgam to dentin. Oper Dent 1994 May-Jun;19(3):97-101.

20. Ratananakin T, Denehy GE, Vargas MA. Effect of condensation techniques on amalgam bond strengths to dentin. Oper Dent 1996 Sep-Oct;21(5):191-195.
21. Vargas MA, Denehy GE, Ratananakin T. Amalgam shear bond strength to dentin using different bonding agents. Oper Dent 1994 Nov-Dec;19(6):224-227.

22. Diefenderfer KE, Reinhardt JW. Shear bond strengths of 10 adhesive resin/amalgam combinations. Oper Dent 1997 Mar-Apr;22(2):50-56.

23. Chang J, Scherer W, Tauk A, Martini R. Shear bond strength of a 4-META adhesive system. J Prosthet Dent 1992 Jan;67(1):42-45.

24. Nakabayashi N, Watanabe A, Gendusa NJ. Dentin adhesion of "modified" 4-META/MMA-TBB resin: function of HEMA. Dent Mater 1992 Jul;8(4):259-264.

25. Hasegawa T, Retief DH, Russell CM, Denys FR. A laboratory study of the Amalgambond Adhesive System. Am J Dent 1992 Aug;5(4):181-186.

26. Kamel MM, Elsayed HY, Abdalla AI, Darrag AM. The effect of water storage on micro-shear bond strength of contemporary composite resins using different dentin adhesive systems. Tanta Dent J 2014 Apr;11(1):47-55.

27. Pashley EL, Comer RW, Parry EE, Pashley DH. Amalgam buildups: shear strength and dentin sealing properties. Oper Dent 1991 May-Jun;16(3):82-89.

28. Overton JD, Vance RI. Effect of adhesive volume on the bond strength of bonded complex amalgam restorations. Am J Dent 2005 Dec;18(6):320-322.

29. Barkmeier WW, Gendusa NJ, Thurmond JW, Triolo PT Jr. Laboratory evaluation of Amalgambond and Amalgambond Plus. Am J Dent 1994 Oct;7(5):239-242.

30. Miyazaki M, Ando S, Hinoura K, Onose H, Moore BK. Influence of filler addition to bonding agents on shear bond strength to bovine dentin. Dent Mater 1995 Jul;11(4): 234-238.

31. Staninec M, Giles WS, Saiku JM, Hattori M. Caries penetration and cement thickness of three luting agents. Int J Prosthodont 1988 Nov-Dec;1(3):259-263.

32. Cobb DS, Denehy GE, Vargas MA. Amalgam shear bond strength to dentin using single-bottle primer/adhesive systems. Am J Dent 1999 Oct;12(5):222-226.

33. Li Y, Swartz ML, Phillips RW, Moore BK, Roberts TA. Effect of filler content and size on properties of composites. J Dent Res 1985 Dec;64(12):1396-1401.

34. Braem M, Lambrechts P, Van Doren V, Vanherle G. The impact of composite structure on its elastic response. J Dent Res 1986 May;65(5):648-653.

35. Ruzickova T, Staninec M, Marshall GW, Hutton JE. Bond strengths of the adhesive resin-amalgam interface. Am J Dent 1997 Aug;10(4):192-194

36. de Menezes MJ, Arrais CA, Giannini M. Influence of lightactivated and auto- and dual-polymerizing adhesive systems on bond strength of indirect composite resin to dentin. J Prosthet Dent 2006 Aug;96(2):115-121.

37. Cianconi L, Conte G, Mancini M. Shear bond strength, failure modes, and confocal microscopy of bonded amalgam restorations. Dent Mater J 2011 Mar;30(2):216-221.

38. Ruyter E. Composite dental restorative materials. Tandlaegebladet 1985 Jan;89(2):67-70.

39. Morrill F, Galburt R, Kuzel G, Zive M, Habib C. Comparison of different shaped particles of amalgam alloy bonded to composite and dentin with 4-methacryloxyethyl trimettalite anhydride. J Dent Res 1994 Mar; 73(1):221.

40. Cooley RL, Tseng EY, Barkmeier WW. Dentinal bond strengths and microleakage of a 4-META adhesive to amalgam and composite resin. Quintessence Int 1991 Dec;22(12):979-983. 
41. Chen RS, Liu CC, Cheng MR, Lin CP. Bonded amalgam restorations: using a glass-ionomer as an adhesive liner. Oper Dent 2000 Sep-Oct;25(5):411-417.

42. Belcher MA, Kunsemiller JA. Bonding amalgam to a resinmodified glass-ionomer base. Am J Dent 1999 Dec;12(6): 305-308.

43. Dhanasomboon S, Nikaido T, Shimada Y, Tagami J. Bonding amalgam to enamel: shear bond strength and SEM morphology. J Prosthet Dent 2001 Sep;86(3):297-303.

44. Miller BH, Arita K, Tamura N, Nishino M, Guo I, Okabe T. Bond strengths of various materials to dentin using Amalgambond. Am J Dent 1992 Oct;5(5):272-276.

45. Garcia-Barbero AE, Garcia-Barbero J, Lopez-Calvo JA. Bonding of amalgam to composite: tensile strength and morphology study. Dent Mater 1994 Mar;10(2):83-87.

46. DeSchepper EJ, Cailleteau JG, Roeder L, Powers JM. In vitro tensile bond strengths of amalgam to treated dentin. J Esthet Dent 1991 Jul-Aug;3(4):117-120.

47. Muniz M, Quioca J, Dolci GS, Reis A, Loguercio AD. Bonded amalgam restorations: microleakage and tensile bond strength evaluation. Oper Dent 2005 Mar-Apr;30(2):228-233.

48. Symons AL, Wing G, Hewitt GH. Adaptation of dental amalgam to the cavosurface margin of class I cavity preparations. J Oral Rehabil 1987 Jan;14(1):65-76.

49. Korale ME, Meiers JC. Microleakage of dentin bonding systems used with spherical and admixed amalgams. Am J Dent 1996 Dec;9(6):249-252.

50. Kidd EA. Microleakage in relation to amalgam and composite restorations. A laboratory study. Br Dent J 1976 Nov;141(10):305-310.

51. Grossman ES, Witcomb MJ, Jodaikin A. Elements in marginal seals at amalgam-tooth interfaces. J Dent Res 1986 Jul;65(7):998-1000.

52. Phillips, RW. Skinner's science of dental materials. 9th ed. Philadelphia (PA): W.B. Saunders Co.; 1991. p. 303-347.

53. Jodaikin A. Experimental microleakage around ageing dental amalgam restorations: a review. J Oral Rehabil 1981 Nov;8(6):517-526.

54. Berry FA, Parker SD, Rice D, Munoz CA. Microleakage of amalgam restorations using dentin bonding system primers. Am J Dent 1996 Aug;9(4):174-178.

55. Briso AL, Campos IT, Sundfeld RH, Rodrigues Junior AL, Pimenta LA. Microleakage of adhesively bonded cervical amalgam restorations. Am J Dent 2002 Jun;15(3):173-176.

56. Meiers JC, Turner EW. Microleakage of dentin/amalgam alloy bonding agents: results after 1 year. Oper Dent 1998 Jan-Feb;23(1):30-35.

57. Van Meerbeek B, De Munck J, Yoshida $Y$, Inoue S, Vargas M, Vijay P, Van Landuyt K, Lambrechts P, Vanherle G. Buonocore memorial lecture. Adhesion to enamel and dentin: current status and future challenges. Oper Dent 2003 May-Jun;28(3):215-235.

58. Turner EW, St Germain HA, Meiers JC. Microleakage of dentin-amalgam bonding agents. Am J Dent 1995 Aug;8(4): 191-196.

59. Saiku JM, St Germain HA Jr, Meiers JC. Microleakage of a dental amalgam alloy bonding agent. Oper Dent 1993 Sep-Oct;18(5):172-178.

60. Tangsgoolwatana J, Cochran MA, Moore BK, Li Y. Microleakage evaluation of bonded amalgam restorations: confocal microscopy versus radioisotope. Quintessence Int 1997 Jul;28(7):467-477.
61. Toledano M, Osorio E, Osorio R, Garcia-Godoy F. Microleakage and SEM interfacial micromorphology of amalgam restorations using three adhesive systems. J Dent 2000 Aug;28(6): 423-428.

62. Sano H, Takatsu T, Ciucchi B, Horner JA, Matthews WG, Pashley DH. Nanoleakage: leakage within the hybrid layer. Oper Dent 1995 Jan-Feb;20(1):18-25.

63. Gale MS, Darvell BW. Controlling dentine penetration in computer microleakage tracer mapping. J Dent 1997 Mar;25(2):129-136.

64. Staninec M, Holt M. Bonding of amalgam to tooth structure: tensile adhesion and microleakage tests. J Prosthet Dent 1988 Apr;59(4):397-402.

65. Ben-Amar A, Liberman R, Judes H, Nordenberg D. Long-term use of dentine adhesive as an interfacial sealer under class II amalgam restorations. J Oral Rehabil 1990 Jan;17(1):37-42.

66. Ben-Amar A, Nordenberg D, Liberman R, Fischer J, Gorfil C. The control of marginal microleakage in amalgam restorations using a dentin adhesive: a pilot study. Dent Mater 1987 Apr;3(2):94-96.

67. Charlton DG, Moore BK, Swartz ML. In vitro evaluation of the use of resin liners to reduce microleakage and improve retention of amalgam restorations. Oper Dent 1992 May-Jun;17(3):112-119.

68. Belli S, Unlu N, Ozer F. Effect of cavity varnish, amalgam liner or dentin bonding agents on the marginal leakage of amalgam restorations. J Oral Rehabil 2001 May;28(5):492-496.

69. Yu XY, Wei G, Xu JW. Experimental use of a bonding agent to reduce marginal microleakage in amalgam restorations. Quintessence Int 1987 Nov;18(11):783-787.

70. Silva e Souza Junior MH, Retief DH, Russell CM, Denys FR. Shear bond strength and microleakage of All-Bond. Am J Dent 1993 Jun;6(3):148-154.

71. Helvatjoglou-Antoniades M, Theodoridou-Pahini S, Papadogiannis Y, Karezis A. Microleakage of bonded amalgam restorations: effect of thermal cycling. Oper Dent 2000 Jul-Aug;25(4):316-323.

72. McCabe JF, Watts DC, Wilson HJ, Worthington HV. An investigation of test-house variability in the mechanical testing of dental materials and the statistical treatment of results. J Dent 1990 Apr;18(2):90-97.

73. Ben-Amar A, Liberman R, Rothkoff Z, Cardash HS. Long term sealing properties of Amalgambond under amalgam restorations. Am J Dent 1994 Jun;7(3):141-143.

74. Mahler DB, Nelson LW. Factors affecting the marginal leakage of amalgam. J Am Dent Assoc 1984 Jan;108(1):51-54.

75. Winkler MM, Moore BK, Rhodes B, Swartz M. Microleakage and retention of bonded amalgam restorations. Am J Dent 2000 Oct;13(5):245-250.

76. Neme AL, Evans DB, Maxson BB. Evaluation of dental adhesive systems with amalgam and resin composite restorations: comparison of microleakage and bond strength results. Oper Dent 2000 Nov-Dec;25(6):512-519.

77. Fritz UB, Finger WJ, Stean H. Salivary contamination during bonding procedures with a one-bottle adhesive system. Quintessence Int 1998 Sep;29(9):567-572.

78. da Silva AF, Piva E, Demarco FF, Correr Sobrinho L, Osinga PW. Microleakage in conventional and bonded amalgam restorations: influence of cavity volume. Oper Dent 2006 May-Jun;31(3):377-383.

79. Marchiori S, Baratieri LN, de Andrada MA, Monteiro Junior S, Ritter AV. The use of liners under amalgam restorations: an 
in vitro study on marginal leakage. Quintessence Int 1998 Oct;29(10):637-642.

80. de Morais PM, Rodrigues Junior AL, Pimenta LA. Quantitative microleakage evaluation around amalgam restorations with different treatments on cavity walls. Oper Dent 1999 Jul;24(4):217-222.

81. Summitt JB, Burgess JO, Berry TG, Robbins JW, Osborne JW, Haveman CW. Six-year clinical evaluation of bonded and pin-retained complex amalgam restorations. Oper Dent 2004 May-Jun;29(3):261-268.

82. Summitt JB, Burgess JO, Berry TG, Robbins JW, Osborne JW, Haveman CW. The performance of bonded vs. pin-retained complex amalgam restorations: a five-year clinical evaluation. J Am Dent Assoc 2001 Jul;132(7):923-931.

83. Belcher MA, Stewart GP. Two-year clinical evaluation of an amalgam adhesive. J Am Dent Assoc 1997 Mar;128(3):309-314.

84. Davis R, Overton JD. Efficacy of bonded and nonbonded amalgam in the treatment of teeth with incomplete fractures. J Am Dent Assoc 2000 Apr;131(4):469-478.

85. Al-Omari QD, Al-Omari WM, Omar R. Factors associated with postoperative sensitivity of amalgam restorations. J Ir Dent Assoc 2009 Apr-May;55(2):87-91.

86. Ben-Amar A, Cardash HS, Judes H. The sealing of the tooth/ amalgam interface by corrosion products. J Oral Rehabil 1995 Feb;22(2):101-104.

87. Smales RJ, Wetherell JD. Review of bonded amalgam restorations, and assessment in a general practice over five years. Oper Dent 2000 Sep-Oct;25(5):374-381.

88. Mahler DB, Engle JH, Simms LE, Terkla LG. One-year clinical evaluation of bonded amalgam restorations. J Am Dent Assoc 1996 Mar;127(3):345-349, quiz 391.

89. Browning WD, Johnson WW, Gregory PN. Reduction of postoperative pain: a double-blind, randomized clinical trial. J Am Dent Assoc 1997 Dec;128(12):1661-1667.

90. Gordan VV, Mjor IA, Hucke RD, Smith GE. Effect of different liner treatments on postoperative sensitivity of amalgam restorations. Quintessence Int 1999 Jan;30(1):55-59.

91. Kennington LB, Davis RD, Murchison DF, Langenderfer WR. Short-term clinical evaluation of post-operative sensitivity with bonded amalgams. Am J Dent 1998 Aug;11(4):177-180.

92. Subay RK, Cox CF, Kaya H, Tarim B, Subay AA, Nayir M. Human pulp reaction to dentine bonded amalgam restorations: a histologic study. J Dent 2000 Jul;28(5):327-332.

93. WHO. Future use of materials for dental restoration: report of the meeting convened at WHO HQ. Geneva: World Health Organization; 2009. p. 65.

94. Risher, JF. Elemental mercury and inorganic mercury compounds: human health aspects. Geneva: World Health Organization: joint sponsorship of the United Nations Environment Programme, the International Labour Organization, and the World Health Organization; 2003. p. 61.

95. Dye BA, Schober SE, Dillon CF, Jones RL, Fryar C, McDowell $\mathrm{M}$, Sinks TH. Urinary mercury concentrations associated with dental restorations in adult women aged 16-49 years: United States, 1999-2000. Occup Environ Med 2005 Jun;62(6):368-375.

96. USPHS DoHa. Dental amalgam: a scientific review and recommended public health service strategy for research, education and regulation. Washington (DC): University of Michigan Library; 1993. p. 216.

97. Bellinger DC, Trachtenberg F, Barregard L, Tavares M, Cernichiari E, Daniel D, McKinlay S. Neuropsychological and renal effects of dental amalgam in children: a randomized clinical trial. JAMA 2006 Apr;295(15):1775-1783.

98. AMAP/UNEP. Technical background report for the global mercury assessment 2013. Geneva/Oslo: Arctic Monitoring and Assessment Programme/UNEP Chemicals Branch; 2013.

99. Nagpal N, Bettiol SS, Isham A, Hoang H, Crocombe LA. A review of mercury exposure and health of dental personnel. Saf Health Work 2017 Mar;8(1):1-10.

100. Norwegian Ministry of the Environment. Amendment of regulations of 1 June 2004 no 922 relating to restrictions on the use of chemicals and other products hazardous to health and the environment. Oslo: Norwegian Ministry of the Environment; 2008.

101. KIFS. The Swedish Chemicals Agency's chemical products and biotechnical organisms regulations. Sweden: KIFS; 2008. [cited 2008 May 14]. Available from: http://www.government.se/contentassets/12c4d85c2ca64d05827fc131f1a47ab9/ sweden-will-ban-the-use-of-mercury.

102. Mudgal, S.; Long, LV.; Mitsios, A.; Pahal, S.; De Toni, A.; Hylander, L. Study on the potential for reducing mercury pollution from dental amalgam and batteries. Final report prepared for the European Commission-DG ENV. Paris: BIO Intelligence Service; 2012.

103. Health and Environment Alliance, HCwH. Mercury and dental amalgams. Brussels: Health and Environment Alliance; 2007.

104. Beazoglou T, Eklund S, Heffley D, Meiers J, Brown LJ, Bailit H. Economic impact of regulating the use of amalgam restorations. Public Health Rep 2007 Sep-Oct;122(5):657-663.

105. World Dental Federation. General assembly resolution, September 2010. Geneva; 2010.

106. Lynch CD, Wilson NH. Managing the phase-down of amalgam: part I. Educational and training issues. Br Dent J 2013 Aug;215(3):109-113.

107. Eriksen HH, Perrez FX. The Minamata Convention: A Comprehensive Response to a Global Problem. Rev Eur Compar Int Environ Law 2014 Aug;23(2):195-210.

108. Vargas CM, Crall JJ, Schneider DA. Sociodemographic distribution of pediatric dental caries: NHANES III, 1988-1994. J Am Dent Assoc 1998 Sep;129(9):1229-1238.

109. Bogacki RE, Hunt RJ, del Aguila M, Smith WR. Survival analysis of posterior restorations using an insurance claims database. Oper Dent 2002 Sep-Oct;27(5):488-492.

110. Fleisch AF, Sheffield PE, Chinn C, Edelstein BL, Landrigan PJ. Bisphenol A and related compounds in dental materials. Pediatrics 2010 Oct;126(4):760-768.

111. Polydorou O, Konig A, Hellwig E, Kummerer K. Long-term release of monomers from modern dental-composite materials. Eur J Oral Sci 2009 Feb;117(1):68-75.

112. Yang J, Chan KM. Evaluation of the toxic effects of brominated compounds (BDE-47, 99, 209, TBBPA) and bisphenol A (BPA) using a zebrafish liver cell line, ZFL. Aquat Toxicol 2015 Feb;159:138-147. 